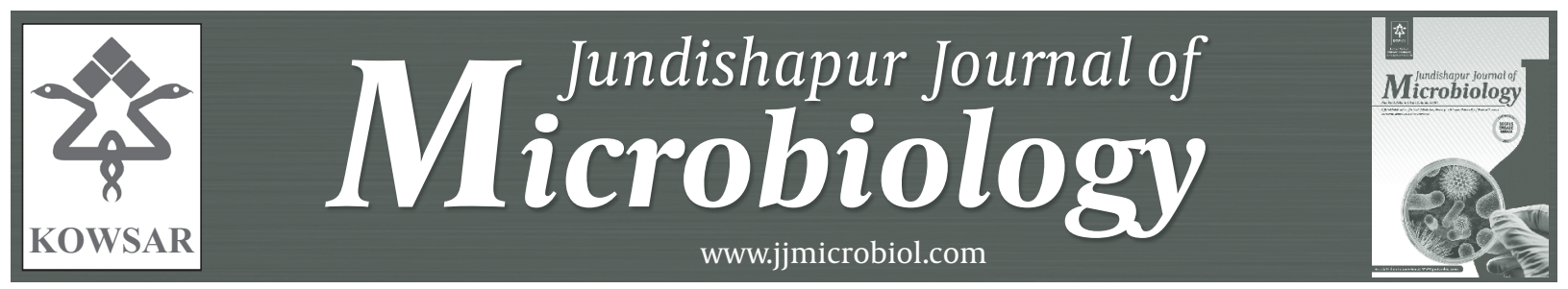

\title{
Prevalence of Fungal Allergens in Respiratory Allergic Patients in Ahvaz City, Southwest Iran
}

\author{
Abdol Hussein Shakurnia ${ }^{1}$, Mohammad Ali Assarehzadegan ${ }^{1,{ }^{*},}$, Akram Amini ${ }^{2}$, Ghodratol- \\ lah Shakerinejad ${ }^{2}$
}

${ }^{1}$ Department of Immunology, Faculty of Medicine, Ahvaz Jundishapur University of Medical Sciences, Ahvaz, IR Iran

${ }^{2}$ Khuzestan Jahad daneshgahi Medical Center, Ahvaz, IR Iran

*Corresponding author: Mohammad Ali Assarehzadegan, Department of Immunology, Faculty of Medicine, Ahvaz Jundishapur University of Medical Sciences, Ahvaz, IR Iran. Tel:+98-6113332036, Fax:+98-6113332036, E-mail: shakurnia@yahoo.com.

\begin{abstract}
A B S T R A C T
Background: Fungi are ubiquitous in our environment and they are one of the important causes of allergic diseases. Identification of the most common aeroallergens to which patients are sensitized in a specific area is important in the diagnosis and treatment of allergic rhinitis. Objectives: The purpose of this study was to determine the prevalence of skin reactivity to common fungal allergens and total IgE in patients with allergic rhinitis in Ahvaz city.

Patients and Methods: In this cross sectional study, 295 volunteers with the signs and symptoms of allergic diseases who referred to the Khuzestan Jahad Daneshgahi Medical Center in Ahvaz during 2010 were investigated. All patients were subjected to skin prick test (SPT) with common allergenic extracts. Data were analyzed by SPSS-18 software using Chi square test.

Results: Seventy subjects, comprising $23.7 \%$ of the study group had positive skin test to at least one of the fungal allergens. The prevalence rate of sensitivity to fungal allergens was as follow:Cephalosporin 11.5\%; mold mix 9.8\%; Penicillium mix 9.5\%; Alternaria mix 8.1\%; and Aspergillus 5.1\%. Mean total IgE in patients with SPT was significantly higher than in patients without any positive skin prick test (251 vs. $125 \mathrm{IU} / \mathrm{mL}, \mathrm{P}=$ 0.001). There was no statistical difference in the prevalence of sensitization to these allergens between two sexes; whereas, 15-35 age groups had significantly higher rates of allergy to fungal allergens $(\mathrm{P}=0.047)$.

Conclusions: Fungal sensitization is a relatively common finding among patients with allergic rhinitis. Elimination or reduction of mold exposure in allergic patients is of special consideration and measures to reduce environmental factors which facilitate mold growth and proliferation are very important.
\end{abstract}

Keywords: Allergy; Fungal Allergen; Skin Prick Test

Copyright $($ 2013, Ahvaz Jundishapur University of Medical Sciences; Published by Kowsar Corp.

-Article type: Research Article; Received: 25 Apr 2012; Revised: 17 Jul 2012; Accepted: 04 Aug 2012; Epub: 01 Jun 2013; Ppub: Jun 2013

-Implication for health policy/practice/research/medical education:

Identifying and determining the most common allergens in the region can provide the necessary recommendations to patients took an important step in controlling and preventing disease. The information obtained in the present study contributes toward a better understanding of the pattern of occurrence of fungal allergy in region, and may be valuable for clinicians, allergists and epidemiologists.

Please cite this paper as:

Shakurnia AH, Assarehzadegan MA, Amini A, Shakerinejad G. Prevalence of Fungal Allergens in Respiratory Allergic Patients in Ahvaz City, Southwest Iran. Jundishapur J Microbiol. 2013;6(4):e4864. DOI: 10.5812/jjm.4864

Copyright (C) 2013, Ahvaz Jundishapur University of Medical Sciences; Published by Kowsar Corp.

This is an Open Access article distributed under the terms of the Creative Commons Attribution License (http://creativecommons.org/licenses/by/3.0), which permits unrestricted use, distribution, and reproduction in any medium, provided the original work is properly cited. 


\section{Background}

Allergic rhinitis is one of the most common chronic conditions, affecting $10 \%$ to $30 \%$ of adults and up to $40 \%$ of children. Many epidemiological studies have revealed a progressive increase of the allergic rhinitis during recent decades (1-3). Allergic rhinitis is characterized by nasal symptoms including sneezing, runny nose, itching and nasal congestion. Allergic rhinitis caused by a complex interaction of genetic factors and environmental influences. One of the most important environmental factors is aeroallergens, such as pollens, fungal spores, house dust mites, etc $(2,4)$.

Ahvaz, the capital of Khuzestan located in the southwest of Iran, is a tropical area with an approximate population of 1.4 millions (census 2006). In our regions, the dust storms were a common phenomenon in some days in spring and summer but now it may occur almost all of the year. It is due to persistent drought, reduced rainfall, lower relative humidity environments, uncontrolled use of water resources in desert areas, loss of canebrake and war during a 28-year period including: the Iran-Iraq War (1980-1988), the Gulf War (1990-1991), and the 21-year crisis in Iraq (1990-2011) (5).

The role of fungi in allergic diseases is well documented. Airborne fungal allergenic spores have been implicated as one of cause of allergic respiratory diseases in our region and neighbour countries $(2,6,7)$. Molds are ubiquitous in our environment and are common allergens in allergic diseases. Mold spores can be found in outdoor or indoor environments, but exposure can also occur by having contact with saprophytic species or by ingestion of edible mushrooms (8-12).

Several species and genera have been reported to cause fungal allergy. Epidemiological, environmental, and clinical research was focused on relevant species like $\mathrm{Al}$ ternaria, Aspergillum and Penicillium $(13,14)$. Several epidemiological and diagnostic studies reported variable prevalence of allergic reactivity to fungi by means of skin testing or IgE detection $(8,15,16)$.

\section{Objectives}

Due to diverse distribution and pattern of aeroallergens in different regions, identification and determination of common allergens is essential $(1,2,17,18)$, and lack of data on prevalence of sensitization to fungal allergens in our region, the current study was conducted to evaluate the prevalence of positive skin test to fungal allergens among allergic rhinitis patients in Ahvaz to develop better strategies for prevention, management and treatment of allergic rhinitis.

\section{Patients and Methods}

This cross-sectional study was conducted in the Immunology department of Ahvaz Jundishapur University of Medical Sciences. The study group included 295 patients with diagnosed allergic rhinitis. These patients were referred to the clinic of Khuzestan Jahad Daneshgahi Medical Center during 2010. We selected allergic rhinitis patients who had been ill for a minimum of 1 year to establish the diagnosis rhinitis such as: symptoms of chronic nasal problems, with sneezing or a runny or blocked nose in the absence of a cold or flu.

Patients with chronic sinusitis or other infective causes of chronic rhinitis and history of medication including antihistamines, steroids and other drugs considered to affect skin prick testing were excluded. Data about demographic variable of patients including sex, age, symptoms and sign of the disease, family history of allergic disease were obtained by a questionnaire. Skin prick tests with common regional fungal allergen extracts (HollisterStier, USA) were performed in all patients by an immunologist, accordance with published guidelines (19).

These allergens used in this study included extracts of fungal such as Alternaria Mix, Aspergillus fumigatus, Cephalosporium acremonium, Penicillium Mix, and Mold mix (Table). These fungal allergens were the most common airborne fungi in many areas with similar climate within our region $(20,21)$.

The skin prick test was performed on healthy skin on the volar surface of the forearm. The test sites were placed 20-30 $\mathrm{mm}$ apart approximately $5 \mathrm{~cm}$ below the elbow and $5 \mathrm{~cm}$ above the wrist. A drop from each extract was applied to the skin and then the skin was pricked through each drop using a sterile lancet. Histamine hydrochloride $(10 \mathrm{mg} / \mathrm{mL})$ and glycerol saline were used as positive and negative controls, respectively.

The mean wheal size was recorded after 15 minutes and SPT was regarded as positive with a wheal size of minimum 3-mm larger than the negative control. Serum samples from all patients were collected and were stored at $-20{ }^{\circ} \mathrm{C}$ until tested. Total IgE was determined in all serum samples with a commercially available enzyme immunoassay kit (DIAPLUS, Canada) according to the manufacturer's instructions. Based on the kit's manual, all values higher than $100 \mathrm{IU} / \mathrm{mL}$ were considered as high total IgE.

Qualitative data are presented as frequencies (\%) and quantitative data as mean and standard deviation (SD). Data were analyzed by SPSS, version 18 . Group differences were studied using the chi-squared test for categorical variables or independent t-test for continuous variables. A $P$-value $<0.05$ in the 2 -tailed test was considered significant.

\section{Results}

In this study, 295 allergic rhinitis patients, 52.5\% males 
and $47.5 \%$ females, aged $4-70$ years (mean age $32 \pm 14.3$ ) were tested for skin prick test reactivity. The population included $40 \%$ employee, $22.4 \%$ students, $21.7 \%$ housekeeper, $11.9 \%$ salesman and $4.1 \%$ unemployed. The mean duration of their symptoms was 7 years with a range of 1 to 20 years. Positive personal history of atopy exists in $43.7 \%$ of patients for 5 years, in $54.3 \%$ higher than 5 years; and $64.4 \%$ of them had positive familial history of atopy.

The clinical diagnoses of patients before SPT were runny nose (85.1\%), sneezing (79.3\%), itchy nose (62.7\%), eye redness (47.1\%) and urticaria (34.6\%). Of 295 patients with allergic rhinitis (AR), 275 patients (92.3\%) reported that they used drugs to improve allergy symptoms. Of 295 patients, 70 subjects (23.7\%) had a positive SPT to at least one fungal allergen. The overall rate of sensitization to any fungal allergen was C.acremonium (11.5\%), Mold mix (9.8\%), Penicillium mix (9.5\%), Alternaria mix (8.1\%), and
A.fumigatus (5.1\%) (Figure).

Prevalence of fungal allergy in males was $23.2 \%$ and in females was $24.3 \%$; and differences were not significant $(P=0.61)$. There was a significant difference between age groups with regard to sensitization to fungal allergy $(P$ $=0.047$ ). Prevalence of fungal allergy in patients below14 years old was $17.1 \%$, 15-35 years old was $30.4 \%$ and higher than 35 years old was $18.5 \%$.

The mean and standard deviation $( \pm S D)$ of serum total IgE level in sensitive group was $251 \pm 182 \mathrm{IU} / \mathrm{mL}$ (median, 235.5) and in non-sensitive group was $125 \pm 143 \mathrm{IU} / \mathrm{mL}$ (median, 79.0). Patients with positive SPT had significantly higher values than patients without positive SPT $(P=0.001)$. Males had higher mean total IgE values than females (265 vs. $236 \mathrm{IU} / \mathrm{mL}, P=0.51$ ), but the difference was not significant.

Table. Prevalence of Positive Skin Prick Test and Total IgE Among Allergic Rhinitis Patients

\begin{tabular}{|c|c|c|c|c|c|c|}
\hline \multirow[t]{2}{*}{ Fungal Allergens } & \multicolumn{2}{|c|}{ Sex, No. (\%) } & \multicolumn{2}{|c|}{ Age Groups, No. (\%) } & \multirow[b]{2}{*}{$\geq 35$} & \multirow{2}{*}{$\begin{array}{l}\text { Total IgE, } \\
\text { IU/mL }\end{array}$} \\
\hline & Male & Female, & $\leq \mathbf{1 4}$ & $15-34$ & & \\
\hline Alternaria mix ${ }^{a}$ & $15(9.7)$ & $9(6.4)$ & $1(2.4)$ & $16(11.9)$ & $7(5.9)$ & 292 \\
\hline A.fumigates & $5(3.2)$ & $10(7.1)$ & $2(4.9)$ & $9(6.7)$ & $4(3.4)$ & 236 \\
\hline C.acremonium & $20(12.9)$ & $14(10.0)$ & $2(4.9)$ & $21(15.6)$ & $11(9.2)$ & 221 \\
\hline Penicillium mix & $14(9.0)$ & $14(10.0)$ & $4(9.8)$ & $14(10.4)$ & $10(8.4)$ & 260 \\
\hline Mold mix ${ }^{C}$ & $17(11.0)$ & $12(8.6)$ & $3(7.3)$ & $18(13.3)$ & $8(6.7)$ & 233 \\
\hline Total & $36(23.2)$ & $34(24.3)$ & $7(17.1)$ & $41(30.4)$ & $22(18.5)$ & 251 \\
\hline
\end{tabular}

${ }^{a}$ Alternaria mix (Alternaria tenuis, Hormodendrum cladosporioides)

b Penicillium mix (P. digitatum, P. expansum, P. glaucum, P. roseum, P. notatum)

C Mold mix [Alternaria tenuis, Aspergillus Mix (A. fumigatus, nidulans, niger, terreus), Hormodendrum cladosporioides, Penicillium mix (P. digitatum expansum, glaucum, notatum, roseum)

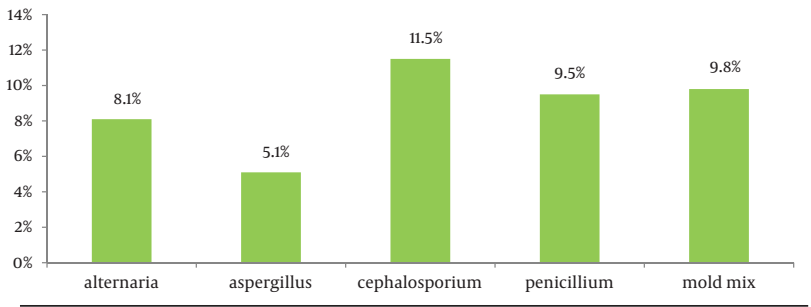

Figure. Frequency of Skin Prick Test Reactivity to Fungal Allergens Among Patients With Allergic Rhinitis

\section{Discussion}

In the current study, the results showed that $23.7 \%$ of the patients were sensitive to at least one of the studied fungal species allergens. To our knowledge, current study is the first report of sensitization to molds allergens in our region. Several studies revealed that fungal spores are present in the atmosphere worldwide (22-24). Multiple species may be observed at any time of the year, but in desert climate like our region, with hot summers and mild winters, spore numbers may peak during fall, winter and spring then decrease with hotter temperatures, and are absent, at least outdoors, in middle of the summer.

Epidemiological studies have been performed on the sensitivity to the fungi allergens in all around the world, including Iran, which were different; depend on the ethnic and geographical conditions. In a study on the 306 patients with AR in Mashhad, Northeast of Iran, the sensitivity rate for fungi was $9.2 \%$ in total but $11.5 \%$ for Alternaria, $11.8 \%$ for Aspergillus and mold mix was $8 \%$ (2). In another study on 212 patients with AR in Shiraz Southern part of Iran, $8.3 \%$ had positive reaction to the fungi allergens. The values for different allergens were 3.7\% for Alternaria and 2.2\% for Aspergillus (25).

Higher rates of sensitization to molds are found in tropical countries like Singapore and Malaysia (26, 27). In a study on 85 patients with allergic rhinitis, in Malaysia, prevalence of allergy to Alternaria and Aspergillus were $12.9 \%$ and $12.2 \%$, respectively (27). Differences in the rate of positive SPT can be due to various factors such as number of allergens tested, climatic region and age of patients. With regard to optimum growing conditions, including 
high humidity for molds $(28,29)$, Unexpectedly, this particular allergy was also found in hot and dry regions, like Saudi Arabia (6) and Kuwait (9, 30), It might be associated with increasing the use of air conditioners inside the houses which make good environment for molds to grow and increase exposure to their allergens $(26,28)$.

The most prevalent sensitizing mold in our study was C. acremonium followed by Penicillium spp.Other molds like Aspergillus and Alternaria are usually found indoors, and SPT to these allergens showed to some extent a low positive result in our study, compared to other reports $(25,31)$. As far as Cephalosporium spp. is concerned, it is also considered as a major allergenic factor responsible for causing the respiratory allergy symptoms in our area, with a percentage of skin positivity in allergic patients of about $11.5 \%$.

The spores of Cephalosporium spp. probably are the most abundant in this area. However further studies are needed to clarify this issue. Skin prick test sensitivity to Aspergillus spp. reached up to 5.1\% in allergic individuals. This percentage might have been expected to be lower, in as much as Aspergillus spores are very common in domestic environment. Our results about the importance of fungal allergy can be explained by consideration of the geo-climatic parameters in our area. Studies have shown that temperature, precipitation, relative humidity and atmospheric $\mathrm{CO} 2$ influence fungi production and concentration in the atmosphere and consequently increase exposure to these allergens $(24,32)$.

Because of the lack of aerobiological information about the atmospheric load of different fungi in our area, we cannot conclude whether the high prevalence of fungi sensitization is related to the high exposure rate or the high potency of fungal allergens. There was no significant difference in prevalence of fungal allergy between both sexes. This was also true considering sensitization to each allergen group; therefore in our study, the influence of sex was weak $(P=0.61)$. Therefore, we failed to find a statistically significant correlation between patient reactivity and patients' gender.

In this regard, some studies agree with us $(25,30)$ and others against us $(33,34)$. Of 295 patients with allergic rhinitis, 190 (64.4\%) patients had a family history of allergic disease. There was a significant correlation between SPT reactivity and positive family history $(P<0.005)$. Prevalence of positive skin prick test was higher in patients with 15-34 years old compared to younger than $\leq$ 15 years old and older than 35 years old $(P=0.001)$, but the difference between the latter two age groups was not statistically meaningful $(P>0.05)$, therefore in our study, the prevalence of fungal allergy increases in middle age years.

In the first age groups ( $\leq 15$ year) Penicillium spp. were the most common fungal allergens and in latter two groups C.acremonium. In our study over $60 \%$ of allergic rhinitis patients had elevated total serum IgE levels $(>150$
$\mathrm{IU} / \mathrm{mL}$ ). Total serum IgE measuring and skin prick testing are the simple and available tools for evaluation of allergic patients and determination of the diseases frequency in communities. However, elevated total serum IgE levels have sometimes considered as the basis of allergy diagnosis, many clinically proven allergic patients may have normal total IgE level, or present with increased IgE levels resulted from non-allergic conditions such as parasitic infections.

In conclusion, this study showed that the prevalence of fungal allergens in Ahvaz, based on SPT, was 23.7\%; and the high level of sensitization was observed with $C$. acremonium. Our results are compatible with similar studies carried out in other parts of the country and other countries with the similar climate. Identifying and determining the most common allergens in the region can provide the necessary recommendations to patients took an important step in controlling and preventing disease. The information obtained in the present study contributes to a better understanding of the pattern of fungal allergy occurrence in region, and may be valuable for clinicians, allergists and epidemiologists.

\section{Acknowledgements}

This study was supported by Ahvaz Jundishapur University of Medical Sciences and in part by Khuzestan Jahad Daneshgahi Medical Center.

\section{Financial Disclosure}

The authors have no conflict of interest to declare.

\section{Funding/Support}

None declared.

\section{Authors' Contribution}

None declared.

\section{References}

1. Aburuz S, Bulatova N, Tawalbeh M. Skin prick test reactivity to aeroallergens in Jordanian allergic rhinitis patients. East Mediterr Health J. 2011;17(7):604-10.

2. Fereidouni M, Farid Hossini R, Assarehzadegan MA, Jabberi Azad F, Varasteh AR. skin prick test reactivity to common aeroallergens among allergic rhinitis patients in Mashhad, Iran . Allergol Immunopathol. 2009;37(2):73-79.

3. Ridolo E, Compalati E, Olivieri E, Walter Canonica G. A Review of Allergic Rhinitis. Allergic Rhinitis. 2011;7(1):67-72.

4. Kashef S, Kashef MA, Eghtedari F. prevalence of Aeroallergens in allergic Rhinitis in shiraz. Iran J Allergy Asthma Immunol. 2003;2(4):185-188.

5. Keramat A, Marivani B, Samsami M. Climatic Change, Drought and Dust Crisis in Iran. WASET. 2011(57):10-13.

6. Almogren A. Airway allergy and skin reactivity to aeroallergens in Riyadh. Saudi Med J. 2009;30(3):392-6.

7. Dowaisan A, Al-Ali S, Khan M, Hijazi Z, Thomson MS, Ezeamuzie $\mathrm{CI}$. Sensitization to aeroallergens among patients with allergic rhinitis in a desert environment. Ann Allergy Asthma Immunol. 2000;84(4):433-8. 
8. Mari A, Schneider P, Wally V, Breitenbach M, Simon-Nobbe B. Sensitization to fungi: epidemiology, comparative skin tests, and IgE reactivity of fungal extracts. Clin Exp Allergy. 2003;33(10):1429-38.

9. Ezeamuzie CI, Thomson MS, Al-Ali S, Dowaisan A, Khan M, Hijazi Z. Asthma in the desert: spectrum of the sensitizing aeroallergens. Allergy. 2000;55(2):157-62.

10. Nolles G, Hoekstra MO, Schouten JP, Gerritsen J, Kauffman HF. Prevalence of immunoglobulin E for fungi in atopic children. Clin Exp Allergy. 2001;31(10):1564-70.

11. Crameri R, Blaser K. Allergy and immunity to fungal infections and colonization. Eur Respir J. 2002;19(1):151-7.

12. Tischer CG, Hohmann C, Thiering E, Herbarth O, Muller A, Henderson J, et al. Meta-analysis of mould and dampness exposure on asthma and allergy in eight European birth cohorts: an ENRIECO initiative. Allergy:;66(12):1570-9.

13. Cantani A, Ciaschi V. Epidemiology of alternaria alternata allergy: a prospective study in 6840 Italian asthmatic children. Eur Rev Med Pharmacol Sci. 2004;8(6):289-94.

14. Gioulekas D, Damialis A, Papakosta D, Spieksma F, Giouleka P, Patakas D. Allergenic fungi spore records (15 years) and sensitization in patients with respiratory allergy in Thessaloniki-Greece. $J$ Investig Allergol Clin Immunol. 2004;14(3):225-31.

15. Pulimood TB, Corden JM, Bryden C, Sharples L, Nasser SM. Epidemic asthma and the role of the fungal mold Alternaria alternata. J Allergy Clin Immunol. 2007;120(3):610-7.

16. Goh JC, Juliana J, Malina O, Ngah ZU, Norhafizalena O. Prevalence of Penicillium specific Ig E level and allergy symptoms among office workers in a selected company in Bangi, Malaysia. Trop Biomed. 2007;24(1):37-46.

17. Ahmed A, Minhas K, Micheal S, Ahmad F. Prevalence of skin test reactivity to aeroallergens in the Pakistani population. Public Health. 2011;125(5):324-6.

18. Arbes SJ, Jr, Gergen PJ, Elliott L, Zeldin DC. Prevalences of positive skin test responses to 10 common allergens in the US population: results from the third National Health and Nutrition Examination Survey. J Allergy Clin Immunol. 2005;116(2):377-83.

19. Position paper: Allergen standardization and skin tests. The European Academy of Allergology and Clinical Immunology. Allergy. 1993;48(14 Suppl):48-82.

20. Bahkali AH, Parvez S. Fungal flora in house dust in Riyadh, Saudi Arabia. Mycoses. 1999;42(4):339-43.

21. Ezeamuzie CI, Al-Ali S, Khan M, Hijazi Z, Dowaisan A, Thomson MS, et al. IgE-mediated sensitization to mould allergens among patients with allergic respiratory diseases in a desert environment. Int Arch Allergy Immunol. 2000;121(4):300-7.

22. Horner WE, Helbling A, Salvaggio JE, Lehrer SB. Fungal allergens Clin Microbiol Rev. 1995;8(2):161-79.

23. Oliveira M, Delgado L, Ribeiro H, Abreu I. Fungal spores from Pleosporales in the atmosphere of urban and rural locations in Portugal. J Environ Monit. 2010;12(5):1187-94.

24. Shinn EA, Griffin DW, Seba DB. Atmospheric transport of mold spores in clouds of desert dust. Arch Environ Health. 2003;58(8):498-504.

25. Kashef S, Kashef MA, Eghtedari F. Prevalence of aeroallergens in allergic rhinitis in shiraz. Iran J Allergy Asthma Immunol. 2003;2(4):185-8

26. Kidon MI, See Y, Goh A, Chay OM, Balakrishnan A. Aeroallergen sensitization in pediatric allergic rhinitis in Singapore: is airconditioning a factor in the tropics? Pediatr Allergy Immunol. 2004;15(4):340-3.

27. Wan Ishlah L, Gendeh BS. Skin prick test reactivity to common airborne pollens and molds in allergic rhinitis patients. Med J Malaysia. 2005;60(2):194-200.

28. Prasad C, Hogan MB, Peele K, Wilson NW. Effect of evaporative coolers on skin test reactivity to dust mites and molds in a desert environment. Allergy Asthma Proc. 2009;30(6):624-7.

29. Katz Y, Verleger H, Barr J, Rachmiel M, Kiviti S, Kuttin ES. Indoor survey of moulds and prevalence of mould atopy in Israel. Clin Exp Allergy. 1999;29(2):186-92.

30. Ezeamuzie CI, al-Mousawi M, Dashti H, al-Bashir A, al-Hage M, al-Ali S. Prevalence of allergic sensitization to inhalant allergens among blood donors in Kuwait--a desert country. Allergy. 1997;52(12):1194-200.

31. Mokhtari Amirmajdi M, Mokhtari Amirmajdi NA, Eftekharzadeh Mashhadi I, Jabari Azad F, Tavakol Afshari J, Shakeri MT. Alternaria in patients with allergic rhinitis. Iran J Allergy Asthma Immunol. 2011;10(3):221-6

32. Beggs PJ. Impacts of climate change on aeroallergens: past and future. Clin Exp Allergy. 2004;34(10):1507-13.

33. Sener O, Kim YK, Ceylan S, Ozanguc N, Yoo TJ. Comparison of skin tests to aeroallergens in Ankara and Seoul.J Investig Clin Immunol. 2003;13(3):202-8.

34. Kim J, Hahm MI, Lee SY, Kim WK, Chae Y, Park YM, et al. Sensitization to aeroallergens in Korean children: a population-based study in 2010. J Korean Med Sci. 2011;26(9):1165-72. 